\title{
A Framework for Design Innovation: Present and Future Discussions Marzia Mortati
}

\section{Introduction}

Business practitioners, researchers, management consultant, policymakers, and innovation experts increasingly are interested in understanding the connection between innovation and design. The buzz around this topic has recently intensified, with efforts coming from many sources to understand complex issues, including the following:

- If and where design meets the innovation imperative and the sustainability challenge;

- How this connection could be explained to nondesigners to demonstrate the strategic value of non-technological advancements; and

- How the economic value of design can be explained and measured.

Design seems to have reached a center stage also in innovation policies; and in the agenda of many public bodies; hence, design is moving up the ladder of recognition in industry, the economy, society, and the academy. Despite these achievements, design still seems characterized by much folklore and incomplete statistical evidence, which need to find a proper examination to give this practice and discipline the place it deserves in the innovation picture. To prove its value, design is facing a twofold challenge: On the one hand, it needs to demonstrate to non-designers why, where, and how it can be considered a valuable element in innovation processes; on the other, it is seeking methods and measures to

Recent reports published by the Commission of the European Communities arguing for this re-contextualization include Design as a Driver of User-Centred Innovation (Brussels: Commission Staff Working Paper, 2009); Europe 2020 Flagship Initiative: Innovation Union (Brussels: Commission Staff Working Paper, 2010); Horizon 2020: The Framework Programme for Research and Innovation (Brussels: Commission Staff Working Paper, 2011); and Implementing an Action Plan for Design-Driven Innovation (Brussels: Commission Staff Working Paper, 2013). show a peculiar economic and social value beyond the aesthetics and meanings of products.

In this article I critically examine these issues, focusing in particular on the reasons for the existence of a paradox in the connection of design and innovation, and on how recent initiatives are trying to scope and promote the value of design, as well as its social and economic input to innovation. The argument is extremely timely in sight of the global challenges for socio-economic regeneration and of the need to regenerate many social and civic practices. Much that worked in the past needs a re-contextualization to work today. ${ }^{1}$ How can design (and design research) 
2 One of the first documents released by the Commission of the European Communities stating the importance of design is titled Design as a Driver of User-Centred Innovation. However, further efforts have been developed in its Europe 2020 Flagship Initiative. Innovation Union and in Michael Thomson, Tapio Koskinen, eds. Design for Growth and Prosperity (Helsinki: DG Enterprise and Industry of the European Commission, 2012).

3 Interesting articles reporting on this missing link are Mike Hobday, Anne Boddington, and Andrew Grantham, “An Innovation Perspective on Design: Part 1," Design Issues 27, no. 4 (Autumn 2011): 5-15; Mike Hobday, Anne Boddington, and Andrew Grantham, "An Innovation Perspective on Design: Part 2," Design Issues 28, no. 1 (winter 2012): 18-29; Mike Hobday, Anne Boddington, and Andrew Grantham, "Policies for Design and Policies for Innovation: Contrasting Perspectives and Remaining Challenges," Technovation 32 (2012): 272-81; and Leon Cruickshank, "The Innovation Dimension: Designing in a Broader Context," Design Issues 26, no. 2 (Spring 2010): 17-26.

4 Interesting references reporting on this link include James Utterback et al., Design-Inspired Innovation (London: World Scientific Publishing, 2007); and Rick Poynor, "Down with Innovation: Today's Business Buzzwords Reflect a Bad Attitude About Design," The International Design Magazine 55, no. 3 (May 2008): 41.

5 Joseph A. Schumpeter, The Theory of Economic Development: An Inquiry into Profits, Capital, Credit, Interest and the Business Cycle (New Brunswick (USA) and London (UK): Transaction Publishers, 1934).

Joseph A. Schumpeter, Theorie der wirtschaftlichen Entwicklung [Development Theory Economic] (Leipzig: Duncker und Humblot, 1911). (trad. it. Joseph A. Schumpeter, Teoria dello sviluppo economico (Milano: Etas, 2002). help frame this change? I address this overarching question in the present article, proposing a framework for design in innovation by identifying relevant strategies and scenarios for change and the promising ways in which design is experimenting on the present challenges.

\section{A Discussion of Scholarly Perspectives: Design in Innovation Models and Policies}

Innovation is a term that has recently received increasing attention from European, regional, and national governments as the best path to growth and prosperity. This term characterizes the twentyfirst century by defining a society that constantly struggles to cope with change and large-scale transformations, unlike other moments in history. In the past, kings and popes used to banish innovation, considering it something that could negatively affect people by instilling in them ideas of novelty. Traditions and spiritual beliefs were more important anchors for life.

In contrast, innovation today is part of our everyday conversations. The most important documents envisioning the future of the European economy (i.e., Horizon 2020, Innovation Union) underline the centrality of innovative activity, enlarging its meaning beyond the successful introduction of new products to the market. A winning innovative capacity should value research and development, as well as creativity, services, design, and social assets, ${ }^{2}$ and thus can begin to enlarge the more traditional innovation model connected to big science. The qualitative dimensions introduced have given new importance to the complex relationship between innovation and design, as one of the crucial points where creativity could intervene to reform the current economic framework. Resolving uncertainties and building consistent evidence have thus become central to describing the contribution of design to innovation processes, both in firms and in the public sector. Scholars have highlighted the two-sided paradox, noting both the absence of design from innovation studies and the social sciences, ${ }^{3}$ and the implicit link to innovation granted by many design scholars. ${ }^{4}$ As a result, they have called for further exploration of the most promising methods and practices to link design and innovation.

\section{The Depths of Innovation}

Innovation is an economic concept, having emerged as a promising domain in the Social Sciences in the 1970s. ${ }^{5}$ In this period of history, both the word and the process became emergent research fields, to be investigated through the lens of human behaviors, organizations and firms, business, society, and policies. Joseph Schumpeter provoked much attention by proposing a theory of economic development determined by cycles of innovation. ${ }^{6}$ These 
7 John Sutton, Sunk Costs and Market Structure (Cambridge: MIT Press, 1992), and John Sutton, Technology and Market Structure (Cambridge: MIT Press, 1998).

8 Jean Tirole, The Theory of Industrial Organization (Cambridge: MIT Press, 1995).

9 Mark Dodgson, David M. Gann, and Nelson Philips, The Oxford Handbook of Innovation Management (Oxford: Oxford University Press, 2013).

10 Jan Fagerberg, David C. Mowery, and Richard R. Nelson, The Oxford Handbook of Innovation (Oxford: Oxford University Press, 2005).

11 Alice Lam, "Organizational Innovation," in The Oxford Handbook of Innovation, ed. Jan Fagerberg, David C. Mowery, and Richard R. Nelson (Oxford: Oxford University Press, 2005), 115-47.

12 Richard R. Nelson and Sidney G. Winter, An Evolutionary Theory of Economic Change (Cambridge, MA: Belknap Press of Harvard University Press, 1982).

13 Bengt-Ake Lundvall, ed. National Systems of Innovation: Towards a Theory of Innovation and Interactive Learning (London: Pinter Publishers, 1992); and Richard R. Nelson, National Innovation Systems (Oxford: Oxford University Press, 1993).

14 Bureau of European Policy Advisors (BEPA), Empowering People, Driving Change: Social Innovation in the European Union (Luxembourg: Publications Office of the European Union, 2011).

15 OECD, Oslo Manual (Paris: OECD Publications Service, 2005). cycles were described as dynamic evolutions through which new technologies displace old ones, thus creatively deconstructing the previous economic order and reconstructing a new one. Schumpeter's theories, 100 years ago, contained all the ideas crucial for innovation today, including the centrality of the entrepreneur and the description of this entrepreneurial activity as new combinations of existing knowledge and resources. However, other perspectives also have been developed-some more traditional and established ones, others newer and still in search of further elaboration. A brief exploration of these perspectives and disciplines would include the following:

- Neoclassical theories that consider innovation as one asset of a business strategy aimed at improving revenues;

- Industrial organization and management, which emphasize the idea that firms innovate to maintain or gain a competitive advantage ${ }^{8}$;

- Marketing, which focuses on consumers and statistical market evidence, linked to product differentiation and new product development for capturing demand;;

- Sociology and psychology, which focus on creativity and people's capacity to exploit opportunities ${ }^{10}$;

- Organizational innovation, which considers innovation processes linked to the practices and routines hidden in knowledge acquisition and use ${ }^{11}$;

- Evolutionary approaches comparing innovation systems to eco-systems and proposing a focus on the structure of interactions as the main means to develop knowledge ${ }^{12}$;

- Systemic innovation, which highlights the influence of external institutions and sources on the innovative activities of firms, and the importance of idea circulation ${ }^{13}$; and

- Social innovation, focusing on innovative outcomes for social concerns and aiming at creating value to enhance society's capacity to act. ${ }^{14}$

This wealth of approaches makes the field extremely large, and the idea of innovation becomes multifaceted as it is interpreted from different perspectives. Even the traditional definition proposed by the Oslo Manual cannot capture this complexity: The idea of the successful introduction of a new product, process, or service to the market is quite limited when looking at the big picture..$^{15} \mathrm{~A}$ clear disciplinary choice must be made when interpreting the word "innovation," which otherwise risks remaining an umbrella term. 
16 Ibid.

17 See Hobday, Boddington, and Grantham, "An Innovation Perspective on Design: Part 1," 5-15; and Hobday, Boddington, and Grantham, "An Innovation Perspective on Design: Part 2," 18-29.

18 Peter Gorb, Angela Dumas, "Silent Design," Design Studies 8, no. 3 (1987): 150-56; and Mike Hobday, Anne Boddington, and Andrew Grantham, "Policies for Design and Policies for Innovation: Contrasting Perspectives and Remaining Challenges," Technovation 32 (2012): 272-81.

19 George Cox, Cox Review of Creativity in Business: Building on the UK's Strengths (London: HM Treasury, 2005).

20 Bruce S. Tether, "Think Piece" on the Role of Design in Business Performance (London: Department of Trade and Industry, HM Government, 2005).

\section{Design in the Depth of Innovation}

Pinpointing the perspective of design within innovation is a slippery task. Despite its limitations, the Oslo Manual serves as a valid starting point. ${ }^{16}$ In focusing on the output rather than on the process, the Oslo Manual distinguishes between four types of innovation: (1) product innovation, involving changes in goods and services; (2) process innovation, which includes changes in production cycles and distribution; (3) organizational innovation (i.e., new organizational methods and routines); and (4) marketing innovation, or changes in product design and packaging, retailing, and pricing methods. The recognition of marketing innovation is a first attempt to include design in terms of product, packaging, and retail. However, structured evidence of the relationship between design and innovation is more difficult to find in innovation studies. Only recently have both innovation and design scholars been looking at this connection more critically. In a recent two-part article published in Design Issues, Hobday et al. discuss how, although innovation studies can count on scholars to look at every aspect of the topic of innovation, design is unusually absent. ${ }^{17}$ Instead, design is either mentioned as one of the activities in the innovation sequence-from R\&D to branding and distribution-as a sub-set of $R \& D$, or it does not appear at all. The authors argue that one of the core reasons for this neglect resides in the evolution of innovation studies, which focuses on operational and routine activities but leaves aside creative and non-routine processes like design.

A tension is apparent in the description of design in innovation: On the one hand is a concentration on the aesthetic value and contribution of design to the development of products, services, and communications; on the other, is the importance of its strategic value and systemic approach to problem setting and solving.

From the perspective of design, two main reasons can be identified for the fragmentation of literature that has contributed to its neglect in innovation studies. First, design has always been subject to a silent dimension and a lack of awareness of its real economic value, so that its managers have often handed its activities over to unqualified or non-recognized personnel. ${ }^{18}$ Second, design is concerned mainly with qualitative aspects of innovation, which makes its contribution more difficult to measure with traditional, quantitative indicators.

Few government-commissioned reports try to connect design and innovation in interesting ways. George Cox's description, arguing that design is an activity capable of linking creativity and innovation, is one of the most often used..$^{19}$ Tether provides a review of dozens of contrasting definitions to argue that design should be seen as a core activity for business growth. ${ }^{20}$ 
21 Commission of the European Communities. Design as a Driver of User-Centred Innovation (Brussels: Commission Staff Working Paper, 2009).

22 Ibid., 9 .

23 The statistics are reported in one of the latest presentations on design innovation made by an officer for design at the European Commission: Antti Valle, European Policies Promoting Design-Driven Innovation. Presentation in Helsinki, March 13, 2014.

24 Pietro Micheli, Leading Business by Design (London: Design Council, 2014).

25 Irish Centre for Design Innovation, The Design Difference. A Survey of Design and Innovation Amongst Ireland's SMES (Sligo: Center for Design Innovation, 2007). These reports further outline a few interesting characteristics of design: (1) Design is a bridge between society, technology, and the market that studies users as links between creativity and innovation; (2) design can reinforce innovation as a process and connect each step better, for example by transforming ideas into products more effectively; (3) design can increase sales and return on investment, both by increasing product differentiation beyond price and performance and by rationalizing processes through the holistic vision of a system (production, logistics, product life cycle, etc.); and (4) design can improve the company's culture, reputation, identity, and user relationships.

26 The action plan recognizes three main drivers to improve the integration of design into innovation policies across Europe: promoting an understanding of design's effect on innovation; promoting design-driven innovation in industries to strengthen Europe's competitiveness; and promoting the adoption of design to drive renewal in the public sector. See Commission of the European Communities, Implementing an Action Plan for DesignDriven Innovation (Brussels: Commission Staff Working Paper, 2013).

27 Examples of European design policies in Eastern Europe are particularly relevant, including: Design Bulldozer in Estonia, Design-Driven Innovation in Norway, Design your Profit in Poland.
The perspective currently most acknowledged in Europe is a description of design innovation formed by collecting several definitions from diverse sources. ${ }^{21}$ The authors of the report conclude that "... [d] esign is a multifaceted and broad concept with no commonly agreed definition. There is agreement that design can be both a verb and a noun-an activity (to design) and the results of this activity (a design) - but the understanding of what the activity of design actually entails varies." 22

When looking at the role of design in business innovation, the European Commission is quite clear in stating that it represents an important part of the process and that its integration produces many positive results, among which is economic growth. Recent studies focus on such results, reporting quantitative statistics to support such a claim. For example, a recent survey conducted in Denmark demonstrates that the number of national companies using design strategically has increased from 15\% in 2003 to 21\% in 200723; a recent report from the British Design Council demonstrates 12 business cases in very different sectors where design is not only adding meaning to products, but represents a culturally pervading element ${ }^{24}$; a survey on Irish businesses clarifies that 75\% of SMEs using design are promoters of the most radical type of innovation when developing new products and services. ${ }^{25}$ Further, the last Action Plan for Design-Driven Innovation broadens the scope of design to incorporate business model innovation, organizational innovation, and other forms of nontechnological innovation, stating that design methods can be instrumental when tackling systemic challenges, such as public services renewal. ${ }^{26}$

These signals are the most recent evidence of the increased emphasis on design innovation that has helped design advocates push their ideas further into the strategic agenda of their countries. New design policies have been promoted in recent years, ${ }^{27}$ and new governments have invested in this area, demonstrating that we are in the midst of a crucial moment for the design community as it seeks to make design values and capabilities explicit. ${ }^{28}$

\section{Design-into the Depth of Socially Relevant Innovation}

Closely connected to the emphasis on design innovation in the business context is the increased interest in the connection between design and social innovation. This connection is another significant topic of discussion in Europe, and a symptom of the need to reformulate citizens' rights and duties in terms of social capital, citizen empowerment, and new entrepreneurship. ${ }^{29}$

Although a recent interest in Europe, social innovation is not a new idea; it has emerged more as a concept than as a clear process with recognizable steps and tools. References to it can be found in the writings of important scholars, such as Peter Drucker and Michael Young in the 1960s and Jacque Attali in the 1970s, and 
28 Relevant examples include the Latvian Ministry of Culture's recent promotion of the creation of a Latvian Design Council and of a Creativity Week to bring design closer to local businesses, as well as the Dutch government's launching of Creative Industry Scientific Programme (CRISP) to develop a knowledge infrastructure that can consolidate a leadership position for the Dutch design sector and creative industries.

29 More specifically, social innovation focuses on innovative outcomes for social concerns and relates to new ideas that-when successfully implementedprovoke a positive transformation and improve society's capacity to act.

30 Geoff Mulgan, Social Innovation: What It Is, Why It Matters and How It Can Be Accelerated (Oxford: Skoll Centre for Social Entrepreneurship, University of Oxford, 2007).

31 Marzia Mortati, Systemic Aspects of Innovation and Design: The Perspective of Collaborative Networks (Milan: PoliMl SpringerBriefs, 2013)

32 Charles Landry, The Creative City: A Toolkit for Urban Innovators (London: Earthscan, 2000); and Charles Landry, The Art of City Making (London: Earthscan, 2006)

33 "San Francisco Made," http://www. sfmade.org (accessed September 22, 2014).

34 "Diritto di sapere," http://www.dirittodisapere.it/ (accessed September 22, 2014). earlier, in the writings of prominent sociologists like Karl Marx, Max Weber, and Emile Durkheim. Social innovation includes overlapping areas, encompassing not only innovations with social purposes, but also social entrepreneurship, collaborative practices, and innovation in public policy and governance. However, a few key characteristics can be listed following Mulgan's interpretation: Social innovations are new combinations of existing solutions, rather than totally new endeavors; they involve a cross-disciplinary and cross-expertise approach; they create new compelling relationships that empower people and organizations to thrive long after the completion of a project. ${ }^{30}$

Social innovation is concerned with networks of products, services, people, and organizations; it focuses on people's connectedness, on the strengths and weaknesses of their networks, and on enhancing their collaborative potential. ${ }^{31}$ It encompasses wide areas of transformation, such as production and distribution systems, government processes, and public services efficiency. Cities are crucial laboratories for and examples of social innovation. ${ }^{32}$ Throughout history, they have transformed infrastructures to accommodate the shift in job specializations, from manual skills to knowledge-intensive applications of human expertise.

One current practice in social innovation looks into how this shift could be positively reverted to connect manual skills back into cities and to promote new types of entrepreneurial initiatives and cultural resources. For example, San Francisco Made is reviving manufacturing practices in an urban area. ${ }^{33}$ Its overarching objectives include encouraging local entrepreneurship, creating new job opportunities, contributing to a thriving and sustainable urban economic system, and raising public awareness about the importance of local craft and manufacturing. Diritto Di Sapere is an Italian initiative seeking to encourage active citizenship and open government by granting easier access to public information. ${ }^{34}$ The ultimate goal is to provide diritto di sapere (literally, right to know) to the entire community, in terms of competencies and tools to improve public administration and services. These types of initiatives further envision the transformation of traditional economic and social practices to build a meaningful framework for innovation now. This approach connects design directly to citizens, empowering them to undertake local initiatives; to municipalities and governments, encouraging participatory processes for new urban planning and public services; and to organizations and firms, leveraging specific socio-territorial attributes to create new jobs.

\section{The Challenges of Advocating for Design in Innovation}

In economic climates characterized by budget cuts and scarce resources, design applied to innovation can be particularly relevant because it can provide shorter pay-back periods for investments 
35 Design in European Policy (www.designpolicy.eu), one of the European Design Innovation Initiative (EDII) co-funded projects (EDII was launched in 2011), has identified four main elements that Europe should address to strengthen the connection between design and innovation policies: (1) the importance of advocating design policies across Europe's innovation system by coaching policy makers and introducing design thinking into the policymaking system directly; (2) the importance of building an evidence base to demonstrate the value of design innovation to governments, which is currently provided by only fragmented data; (3) the importance of strengthening the design sector to sustain it as a source of income and economic wealth, and to develop more effective design capabilities; and (4) the importance of fostering an evaluation culture for design policies to make non-technological innovation score as highly as technological innovation in the policy makers' agenda. the sector by $29 \%$ from 2005 to 2010 , and that it is mainly composed of small and young businesses (more than $60 \%$ have less than five employees). Moreover, the report offers details on the whole sector in Britain, including the profiles of companies in which design qualifies, the geographic concentration, the financial performance, the type of clients using these services, and the national competition.

and more efficient processes. This connection reveals a potential for multi-disciplinary integration of environmental, social, and economic considerations into the development of products, services, systems, and business models, and thus calls for our focused attention. However, evidence suggests we have to overcome barriers for the potential of design to be recognized. ${ }^{35}$

Innovation policy has not yet caught up with the strategic potential of design. For example, companies lacking experience in this area-in particular, small and medium-sized enterprises (SMEs) — often don't know where to find design help, unless they seek out national institutions with an established reputation. Further, the current landscape lacks statistical data or indicators to demonstrate and measure design value. Official statistics include very few explicit indicators of design value, so that meanings relevant to design often have to be sought out and interpreted. For example, design could be considered part of the R\&D definition in the Frascati Manual, or in the marketing innovation of the Oslo Manual. However, the majority of design aspects remain scarcely covered in the official Innovation Index and Scoreboards.

Two significant documents have recently been published in the United Kingdom on statistics supporting design. In January 2014, the Department of Culture, Music and Sport released the report, "Creative Industries Economic Estimates"—an official statistic on the economic value of creative industries in Britain. This statistic provides an overview of new jobs created, the contribution to Gross Value Added (GVA), and national exports. Design is identified as a sector that comprises $6 \%$ of British employees and that produces 5.2\% of the overall value of the British economy. Another report, "Design Industry Research," was released in 2010 by the Design Council to report on the results of a national survey of 2,200 design businesses. The survey investigated design teams in enterprises and design consultancies, as well as design professionals working in diverse fields (e.g., communication, interior, product, fashion, service). The results state that in the United Kingdom 232,000 designers work, producing wealth that totals approximately $\$ 23$ billion (about $£ 15$ billion) per year. ${ }^{36}$

Further, sources exist describing creative industries worldwide, such as the "Creative Economy Report," published by UNESCO in 2013. In addition to providing an overview of the creative industries worldwide, one of the interesting points of the report is its proposal of various categories of indicators to measure the outcomes of the sector: economic indicators, to reflect on the value of investments; social indicators, to reflect on the social cohesion developed; cultural indicators, investigating the production of well-being; and environmental indicators, concerning the sustainable development created. These indicators would also be appropriate for understanding the value of design, not only as a sector, but as the system of actors that operate in a field (e.g., schools, 
museums, magazines, professionals, etc.). At the same time, this variety makes measuring, proving, and advocating for design value a highly complex undertaking. Difficulties emerge partly because design innovation is different from traditional linear processes, and it does not correspond to a straight set of stages that commonly start from research and end with product distribution. Design is iterative and recursive, people-centered, constantly diverging and converging. It delineates an approach to define problems with a special focus on people's needs, which has caused the progressive expansion of the concerns of design innovation.

Reflecting on how the picture of innovation is shifting, and how designers are connecting to this evolving image, is thus crucial. In particular, enabling this sort of reflection is the intent of the remainder of the article, which offers prompts to further the discussion of the challenges for the future of this innovation/design research field.

\section{The Assets of a Design Innovation Framework}

This section reflects on the emergence of new practices that push design to ask broader questions, in connection to the changes in consumption and industrial production, in governmental organizations, and in user systems. In particular, a few crucial questions to ask include:

- For what type of industry/business does design work today?

- What does it produce/sell?

- How can this "product" be shaped for a better future?

We explore answers to these questions by proposing three open discussions, in terms of relevant topics that help identify a meaningful framework for design innovation now.

\section{Open Discussion \#1: Strategies for Change}

The discussion about the connection between design and innovation offered throughout the paper is very broad and includes a wide variety of assets and strategies of integration for the two processes. Assuming the perspective of systemic and social innovation, the connection could be described using two polarities:

- More or less power: The higher or lower concentration of power is in the hands of a few, which describes the difference between a top-down and a bottom-up innovation approach.

- More or less knowledge: The higher or lower concentration of specific knowledge is in the context where innovation happens, which describes the difference between an incremental innovation (changes within the existing range of knowledge) and a radical innovation (changes outside the given range of knowledge). 
In other words, two types of transformation can be identified throughout the discussion: first-order change and secondorder change. ${ }^{37}$ In the first case, the description refers to smaller adjustments in a given system; in the second case, qualitative and more radical modifications are included. None of these combinations of power and knowledge is better than the other; rather, the best advantages for the system/society are central. Crossing the given axes of power and knowledge, a $2 \times 2$ matrix comprising four strategies emerges: community-driven strategies, control strategies, emergent strategies, and distributed/collaborative strategies (See Table 1).

Table 1| Strategies for systemic change (Adapted from Mulgan, 2013)

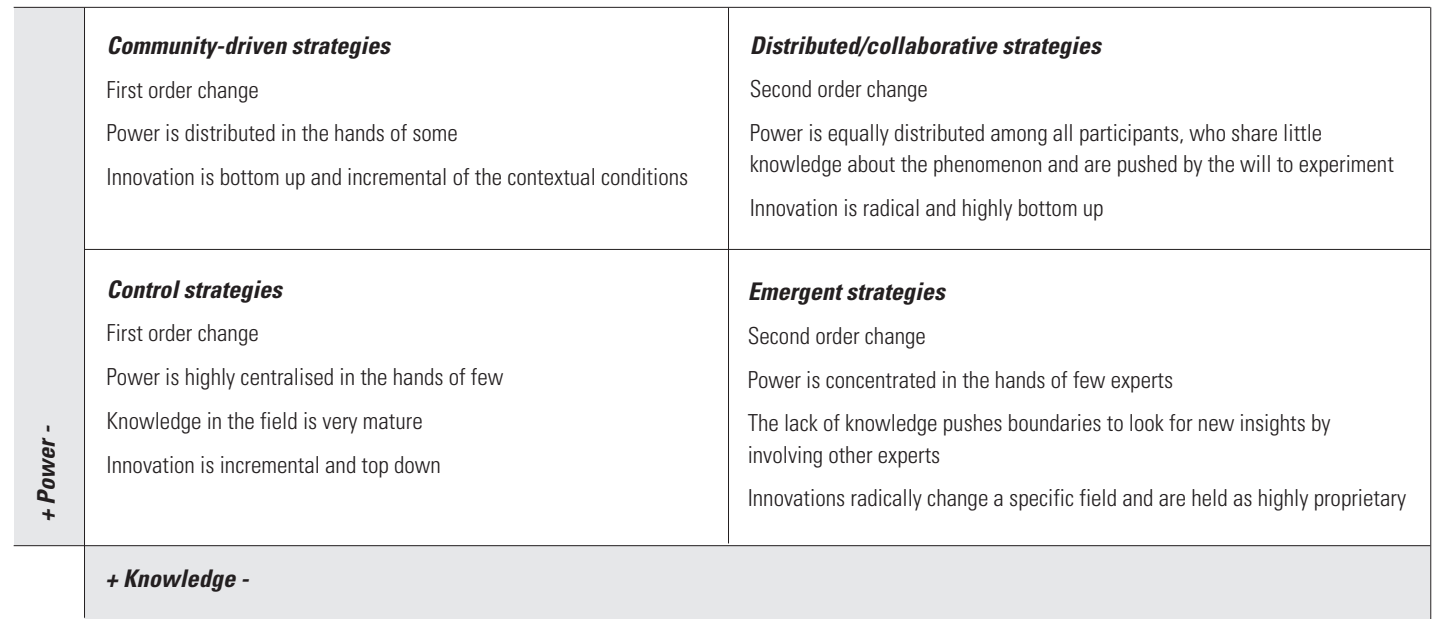

37 Paul Watzlawick, John Weakland, and Richard Fisch, Change: Principles of Problem Formation and Problem Resolution (New York: Norton, 1974).

Community-driven strategies describe a first-order change, in which a group of people engages to improve underlying conditions. In this case, a group of leaders or experts drives a wider network of interested parties through incremental innovations. An example of this case would be the projects developed by Participle, a British organization and consultancy that helps design public services to offer citizens a chance to realize their potential. The organization works with people, experts, and community developers to incrementally change communities and reach a wider vision, built around relational welfare, common sense of belonging, and new ways to use resources.

Control strategies describe situations where knowledge has been developed but not shared. Here, knowledge is concentrated in the hands of a few experts, who are capable of manipulating it for application. Closed-off research labs in big multinationals used to apply this approach, which helped them control Intellectual Property Rights (IPR) and exploit the findings of their research. The majority of novelties produced in this case are incremental because they stem from the same R\&D fountain. Innovation is thus top down and is highly influenced by a few leaders who have the power, knowledge, and money to exploit findings. 
38 "Open Source Ecology," http://opensourceecology.org/ laccessed September 22, 2014).

39 Richard Normann and Rafael Ramirez, "From Value Chain to Value Constellation: Designing Interactive Strategy," Harvard Business Review 71, no. 4 (1993): 65-77.

40 Examples of business models proposed to support the development of collaborative consumption are described in Rachel Botsman, and Roo Rogers, What's Mine Is Yours: How Collaborative Consumption Is Changing the Way We Live (London: HarperCollins Publishers, 2010).

41 New productive technologies, like 3D and $4 \mathrm{D}$ printers, increasingly promote imagining alternative processes for the production of physical goods, opening these possible alternatives to different types of users, as well as expert manufacturers.
Emergent strategies are comparable to the traditional diffusion of new technologies, where the power to do something is in the hands of a few experts, because of both competencies and resources. When technologies or other types of scientific discoveries are relatively new, the knowledge necessary to uncover the full possibilities of such developments is usually specialized in different fields, and the discoveries push the boundaries of scientific research to look for collaboration with other experts. In this case, innovation can take longer to happen because knowledge needs time to evolve into learning and to find the right application. However, these changes can result in very radical modifications of daily habits and social practices.

Distributed/collaborative strategies describe disruptive events where resources are balanced between a broader range of actors, pushed to experiment together to understand a new phenomenon. These strategies underlie bottom-up changes led by culture and behavior, largely rooted in the society and usually manifested because of public demand. For example, a phenomenon can become relevant for the novelty of the knowledge and its potentialities, and because of the rapid diffusion and adoption by citizens. Such is the case with $3 \mathrm{D}$ printers, which are capturing the curiosity and imagination of the public and offering visions for new productive systems. Further, networks of passionate participation in building Wikipedia, in mapping the human genome, or in defining open-source ecologies can also exemplify this strategy. ${ }^{38}$

This exploration of strategies for change is especially relevant in emphasizing that innovation is not just about finding the correct positioning of a brand in the market, but it can look at shaping the whole company. As Normann and Ramirez stated more than ten years ago; “... successful companies conceive of strategy as systematic social innovation: the continuous design and redesign of complex business systems." ${ }^{39}$ This means learning to be creative and to arrange differently existing elements in relevant combinations-a task with which design can help through its systemic problem setting and solving capability.

\section{Open Discussion \#2: New Firms and New Entrepreneurs}

Closely connected to the idea of meaningfully framing the connection between design and innovation is the idea of understanding what enterprises represent today. The need for a fresh understanding is being motivated and emphasized by the emergence of a few significant topics, including the new practices that are helping to reduce consumption by encouraging a more collaborative sense of ownership ${ }^{40}$; the opportunity to rethink production processes and proprietary rights, given new technologies ${ }^{41}$; and the use of information and communication technologies (ICTs) to expand and give new meaning to the involvement of users during the innovation 
42 Open-source projects are multiplying quickly on the Internet by using collaboration and collective intelligence to increase the number of ideas entering the innovation funnel. For example, "Open Structures" explores the possibility of a modular construction model whereby everyone designs for everyone on the basis of one shared geometric grid. See "Open Structures," http://www. openstructures.net/ (accessed September 22, 2014).

43 Henry W. Chesbrough, Wim Vanhaverbeke, and Joel West, eds. Open Innovation: Researching a New Paradigm (Oxford: Oxford University Press, 2006).

44 One well known example is "Ponoko" (https://www.ponoko.com/), a manufacturing platform to have any design produced (accessed September 22, 2014).

45 The project C-Fabriek, developed by "Waag Society" (https://www.waag.org/ $\mathrm{nl})$, is an experiment made of Da Vincilike machines and invented by designers to create manual production plants (accessed September 22, 2014).

46 "Custommade," http://www.custommade.com/ laccessed September 22, 2014).

47 "SlowD," http://www.slowd.it/ (accessed September 22, 2014).

48 "The Third Industrial Revolution," The Economist, April 21, 2012. (http:// www.economist.com/node/21553017) (accessed September 22, 2014).

49 Stefano Micelli, Futuro Artigiano (Venezia: Marsilio, 2011).

50 Bas Van Abel et al., Open Design Now: Why Design Cannot Remain Exclusive (The Netherlands: Bis Publisher, 2011). process. ${ }^{42}$ Building on these fresh ways of thinking, pilot projects are blossoming that can suggest unprecedented ways for generating a phenomenology of firms.

Enterprises traditionally have been considered economic objects from which profit had to be gained. The value of these artifacts is describable with the concept of the stock price, and the main asset is management, as the core activity aimed at satisfying investors' interests. This idea has been dominant for centuries, despite the cycles of economic ups and downs. Recently, the socioproductive crisis, and specifically the need to reform productive cycles toward sustainability and to create a circular economy with renewed job opportunities, has demonstrated the need to edit these concepts, including a shift in thinking about firms' values in terms of social capital, reputation, culture, and relationships. This transformation is an extremely interesting research topic, for which theories are trying to envision new answers. For example, open innovation is a theoretical attempt to open up firms' innovation funnel while maintaining the structure of traditional hierarchical enterprises. ${ }^{43}$

In this area, the situation of designers is a peculiar one. Practices are multiplying that want to reclaim the creativity inherent in a productive process and in doing so to edit a specific conception of industry. Many young practitioners are building self-managed manufacturing plants, both literally and by using online services. They are leveraging the increasing number of online services that offer ready-made production relationships to anyone with an idea ${ }^{44}$; or they're doing so by building their machines directly. ${ }^{45}$ Alternative network-based production processes are complementing the traditional description of industry through projects like "Custommade" ${ }^{\prime 46}$ and SlowD ${ }^{47}$; these platforms try to create new businesses by connecting local craftspeople and people looking for skilled labor. Some observers define these changes as a third industrial revolution ${ }^{48}$; others talk of a craft future that gives new value to manual skills and small-batch productions. ${ }^{49}$ Still others highlight peculiar aspects of the phenomenon, like the possibility of opening up the planning stage of an object to allow for collective development, thus providing insight into a distributed/collaborative strategy for change that is defining new types of firms. These new firms possess almost no internal assets and rely totally on outsourcing. ${ }^{50}$ Their core is not the hardware, the productive plant, or the headquarters: These assets are only the technical means. The heart of the firm is the person with a vision (the Schumpeterian entrepreneur), with his and her ability, motivation, and opportunity to engage for value creation. In this exciting new field, designers-who have long worked waiting for the right firm to buy and produce their ideas-are themselves 
entrepreneurs who can totally revise the logics of power and knowledge to create a firm based on relationships, and on the value of local resources, small numbers, and excellence.

\section{Open Discussion \#3: The Designer-Citizen}

In addition to looking further into and developing their entrepreneurial characteristics, designers are expanding their role in innovation through social responsibilities. They are becoming accountable for the stimulation of critical thinking around innovations, thus joining the peculiarities of two types of figures: the entrepreneur and the craftsperson. Entrepreneurial action is, for Schumpeter, the starting point for transforming society. ${ }^{51} \mathrm{He}$ describes the entrepreneur with specific psychological characteristics that begin with the dream and will to establish a private empire. This drive is complemented by the will to win, to fight, and to succeed, and by the joy of creation. In The Craftsman, Sennet describes the "craftsman" as the special human condition as that of being engaged in the work-in and for itself-and of connecting work to the freedoms of experimentation..$^{52}$

Designers thus consider themselves citizens in the broadest and most engaged sense of the word because, through their visions, they can propose a unique connection of technology, people, and places to create novel solutions for the challenges described above that contain possibilities for development. This vision is quite different from that of the traditional industrial design function. Here, the context was organized into three large groups: the designers, the users, and the providers/manufacturers. These separate entities needed to connect in specific ways to develop larger projects. Thus, each of these groups has become a network-a network of users, of companies, and of designers, connecting to develop novel outputs. This multiplicity of insights, needs, and resources is going to characterize and be subsumed into the design profession and practice of the future, as well as its business models and innovation frameworks.

Consequently, new perspectives, methods, and skill needs emerge for the education of designers, dictated by the necessity to cope with complex changes in socio-economic infrastructures. A first necessity is the skill to listen actively and to converse in ways that focus on and try to understand the values of different experiences. Such capacities are a crucial starting point for creativity because they support observation and recognition of heterogeneous values in cultures and habits. ${ }^{53}$ Further, it allows designers to foster co-production and share creativity by looking into the miscommunications that typically happen at the boundaries and in the midst of collaborations. 
Connected to this sort of communication are the skills to visualize and translate the creative process to ease the exchange of ideas. Visualizations developed through maps, diagrams, and other representations emancipate users to own their own outputs and trigger the engagement of others. Many design scholars have described these abilities. ${ }^{54}$ For example, Rittel argues that the privileged place for design action is the imagination, in which ideas are born and manipulated, and where concepts rather than real resources can be used. The capacity to imagine generates diverse perceptions of reality and can lead to proposals and frameworks that consider resource efficiency.

A third skill relates to negotiating and orchestrating, with an understanding of all stakeholders involved in an issue, so that their participation can be mapped and structured and the conflicts typical in a creative process can be appropriately managed. This relational capacity is connected to the creation of better, more resilient interactions, and to the contribution and empowerment of citizens.

With these skills, the designer-citizen can create that important connection between bees and trees explained by Mulgan as the most promising source of social innovation. ${ }^{55}$ The bees-the sources of creativity-need to meet with trees-the strong institutions-to help new ideas thrive and multiply, in the search for innovation that is meaningful, social, and systemic.

\section{Conclusion}

The intent of this article has been to outline some of the most interesting discussions about the links between design and innovation,

54 Among these scholars are Horst Rittel, "The Reasoning of Designers," Proceedings of the International Congress on Planning and Design Theory (New York: American Society of Mechanical Engineers, 1987); Donald Schön, The Reflective Practitioner: How Professionals Think in Action (New York: Basic Books, 1983); Nigel Cross, "Designerly Ways of Knowing: Design Discipline versus Design Science," Design Issues 17, no. 3 (2001): 49-55; and Brian Lawson and Kees Dorst, Design Expertise (0xford: Architectural Press, 2009).

55 Maria Grazia Mattei, Social Innovation (Milano: Egea, 2013). and to then propose a framework to appropriately describe this connection now. This overview and proposal have pushed our exploration toward imagining a new meaning for the enterprise of the twenty-first century, and an emerging role for the designer in relation to it. However, the reflections proposed are to be considered launching points for wider discussions, from the measurement of the value of design, to the description and prescription of the future roles for designers. The aim of the article has been to develop a framework through which design innovation can be discussed and explored by respecting its multi-faceted nature. Therefore, different perspectives about design innovation have been highlighted, and the hope is that they can be helpful for other academics in all innovation fields to advance both practical and theoretical understandings. 